\title{
Non-invasive Hemodynamic Monitoring of Fluid Resuscitation in Cirrhotic Patients with Acute Kidney Injury
}

\author{
Samir El Hadidy ${ }^{1 \star}$, Ahmed Albadry $^{2}$, Waheed Radwan ${ }^{1}$, Amna Metwaly $^{1}$, Khaled Farouk ${ }^{1}$ \\ ${ }^{1}$ Department of Critical Care, Faculty of Medicine, Cairo University, Giza, Egypt; ${ }^{2}$ Department of Critical Care Medicine, Theodor \\ Bilharz Research Institute, Giza, Egypt
}

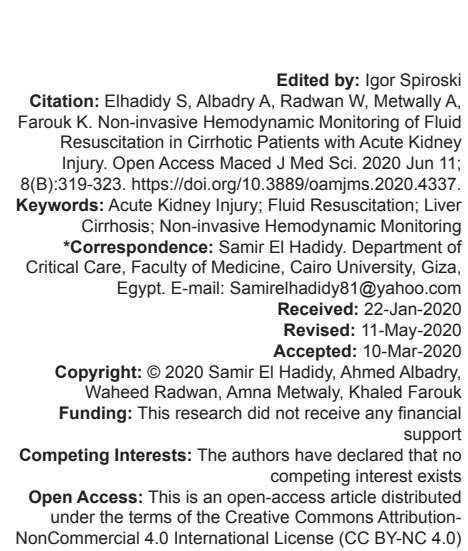

Introduction

Management of cirrhotic patients admitted to intensive care unit (ICU) constitutes a special challenge due to the high morbidity and mortality rates usually encountered with this population. They have significant alterations in their immunological, coagulation, and hemodynamic functions which add to the difficulty of management [1], [2]. Hemodynamic changes include portal hypertension, systemic vasodilation, and hyperdynamic circulation which subsequently result in deteriorated renal and cardiac functions [3].

Acute kidney injury $(\mathrm{AKI})$ is a common life-threatening complication in cirrhotic patients. It is mostly attributed to pre-renal causes, hepatorenal syndrome (HRS), or acute tubular necrosis [4], [5]. Considering the significant hemodynamic changes in cirrhotic patients with $\mathrm{AKI}$, different types of $\mathrm{AKI}$ in those patients can be predicted. Among the various methods of hemodynamic monitoring, echocardiography monitoring proved to be more efficient when compared with other methods, for example, central venous pressure (CVP) monitoring [6]. However, value of this utility in the context of AKI in cirrhotic patients is rarely discussed in the literature.

The present study aims to evaluate the use of echocardiography as a non-invasive hemodynamic monitoring tool for the assessment of volume status and cardiac function before and after volume expansion in patients with liver cirrhosis presented by AKI.

\section{Patients and Methods}

\section{Study design and enrollment criteria}

The present study prospectively recruited a cohort of 40 cirrhotic patients with $\mathrm{AKI}$ admitted to the critical care department at Theodor Bilharz Research Institute, Cairo, Egypt. The study protocol was approved by the local ethical committee.

Patients were included in the study on the basis of Child-Turcotte-Pugh classification for end-stage liver disease and AKI network (AKIN) classification for AKI [7]. Exclusion criteria included pregnancy, volume 
expansion before echocardiography, portal vein thrombosis, tense ascites, transjugular intrahepatic portosystemic shunt, mechanical ventilation, aortic stenosis, dysrhythmia, heart failure, pulmonary hypertension, and chronic renal failure.

\section{Basic evaluation}

All patients were subjected to careful history taking, thorough clinical examination and routine laboratory assessment. HRS was diagnosed according to the following criteria:

1. Liver cirrhosis with ascites.

2. Serum creatinine $>1.5 \mathrm{mg} / \mathrm{dL}$.

3. Absence of shock state.

4. No improvement of serum creatinine (decrease to a level of $1.5 \mathrm{mg} / \mathrm{dL}$ or less) after at least 2 days of diuretic withdraw and volume expansion with albumin (the recommended dose of albumin is $1 \mathrm{~g} / \mathrm{kg}$ of body weight per day up to a maximum of $100 \mathrm{~g} / \mathrm{d}$ ).

5. No current or recent exposure to nephrotoxic drugs and absence of parenchymal disease as indicated by proteinuria $>500 \mathrm{mg} / \mathrm{d}$, microscopic hematuria [8].

(IAP)

\section{Intra-abdominal pressure assessment}

IAP was assessed indirectly through indwelling urinary catheter after instillation of $25 \mathrm{~mL}$ of saline into the bladder then measuring by CVP ruler $60 \mathrm{~s}$ at the end of expiration in supine position. Normal IAP is $5-7 \mathrm{mmHg}$ up to $10 \mathrm{mmHg}$ in critically ill adult patients [9].

\section{Fluid challenge}

Fluid challenge was performed by $500 \mathrm{ml}$ crystalloid ( $\mathrm{NaCl} 0.9 \%$ ) over 20-30 $\min$ [10].

\section{Echocardiographic assessment}

Echocardiographic assessment was performed for all participants and included:

\section{Inferior vena cava (IVC) collapsibility index}

IVC diameter was measured by transthoracic echocardiography by visualizing the IVC as it entered the right atrium (subcostal window, long-axis view). The M-mode cursor was used to create a time-motion image of the IVC diameter just proximal to the junction of hepatic vein that lies approximately $0.5-0.3 \mathrm{~cm}$ proximal to the ostium of the right atrium perpendicular to IVC. IVC diameters were collected over a $20 \mathrm{~s}$ period of spontaneous respiration, the maximum and minimum intraventricular conduction delays were measured.
IVC Collapsibility Index=(IVCD MAX-IVCD MIN)/IVCD MAX×100.

IVC collapsibility index more than or equal to $12 \%$ considered fluid responsiveness.

Left ventricular outflow tract velocity time integral (LVOT VTI) variability index

LVOT VTI was obtained by visualizing the LVOT (apical window, 5-chamber view). The pulsed wave Doppler cursor was placed in the middle of the LVOT just adjacent to the aortic valve. The largest and smallest waveforms were collected over a 20 s period of spontaneous respiration.

LVOTVTI variability index $=\{($ VTImax - VTImin $) /$ [(VTImax-VTImin)/2]×100\%\}

LVOT VTI variability index more than or equal to $12 \%$ considered fluid responsiveness.

\section{Cardiac output (CO)}

We measured $\mathrm{CO}$ before and after fluid challenge; then, the percentage of increase in $\mathrm{CO}$ was calculated.

$$
\mathrm{CO}=\left(\mathrm{SV}^{*} \mathrm{HR}\right) / 1000
$$

Fluid responsiveness defined as increase in CO more than or equal to $15 \%$.

\section{Statistical analysis}

Data were statistically analyzed using the Statistical Package for the Social Sciences (IBM, USA) version 23. The quantitative data were presented as mean and standard deviations or median and interquartile range. Qualitative data were presented as number and percentages. The comparison between two independent groups with qualitative data was done using Chi-square test or Fisher's exact test while comparison between quantitative data was done by independent t-test or Mann-Whitney U-test as appropriate. The comparison between paired quantitative variables was achieved using paired t-test or Wilcoxon rank test. Receiver operator characteristic test was used to determine diagnostic test sensitivity and specificity. $p<0.05$ was considered statistically significant.

\section{Results}

In the present study, fluid responsiveness was achieved in 75 patients $(62.5 \%)$ with pre-renal azotemia with an improvement of $\mathrm{AKI}$ after correction of the intravascular volume status. Forty-five (37.5\%) patients were fluid non-responsiveness and fulfilled the 
criteria for HRS. Hence, we divided our studied patients two groups:

Group 1: Patients with pre-renal azotemia.

Group 2: Patients with HRS.

Comparison between both groups regarding the various clinical variables revealed that Group 1 patients had significantly better AKIN staging and better Child-Pugh scores (Tables 1 and 2).

Table 1: Child-Pugh classification of studied group

\begin{tabular}{llllll}
\hline & & Group 1 no. $=75(\%)$ & Group 2 no. $=45(\%)$ & Test value & p-value \\
\hline Child & B & $33(44.0)$ & $3(6.7)$ & 18.667 & 0.000 \\
& C & $42(56.0)$ & $42(93.3)$ & & \\
\hline
\end{tabular}

Comparison between both groups regarding the echocardiographic data showed that Group 1 patients had significantly higher IVC collapsibility index, LVOT VTI variability index, and \% of CO increase (Table 3).

Table 2: AKIN criteria

\begin{tabular}{lllll}
\hline AKIN & Group 1 no. $=75(\%)$ & Group 2 no. $=45(\%)$ & Test value & p-value \\
\hline 1 & $48(64.0)$ & $12(26.7)$ & 43.594 & 0 \\
2 & $27(36.0)$ & $12(26.7)$ & & \\
3 & $0(0.0)$ & $21(46.7)$ & & \\
\hline AKIN: Acute kidney injury network. &
\end{tabular}

IVC collapsibility index, LVOT VTI variability index, and \% of CO increase showed good predictive value of fluid responsiveness while EF failed to show such value (Table 4, Figures 1-3).

As regard the need for central venous line (CVL) insertion, the use of echocardiography allows to avoid unduly use of central venous catheter in 87 patients ( $72 \%$ of the cases) and hence its complications (Table 5).

Comparison between both groups regarding the in-hospital mortality data showed that Group 2 patients had significantly higher in-hospital mortality (Table 6).

\section{Discussion}

Management of cirrhotic patients with AKI is a complex issue that depends mainly on accurate assessment of intravascular volume status [11]. This study was designed to assess the non-invasive hemodynamic monitoring using echocardiography in evaluation of volume status before and after volume resuscitation in patients with liver cirrhosis presented with $\mathrm{AKI}$
The reported causes of $\mathrm{AKI}$ in the present study include pre-renal azotemia (62.5\%) and HRS (37.5\%). Matching with our result, Warner et al. [12] who studied AKI in 152 hospitalized cirrhotic patients with liver cirrhosis found that $70 \%$ of the patients had pre-renal azotemia.

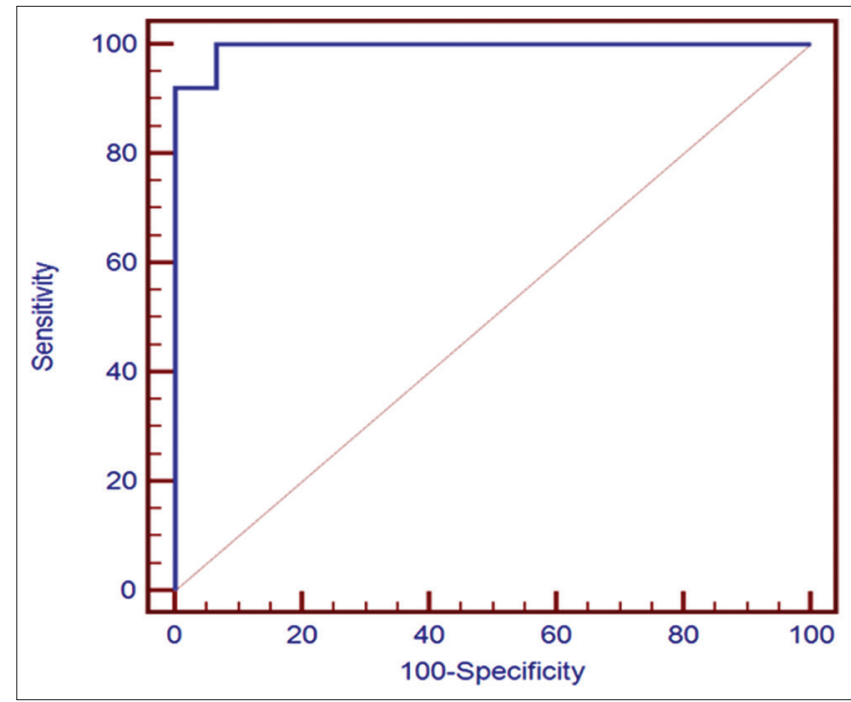

Figure 1: Sensitivity and specificity of inferior vena cava collapsibility index

Fluid responsiveness of these patients was assessed using two dynamic echocardiographic measures (IVC collapsibility index and LVOT VTI

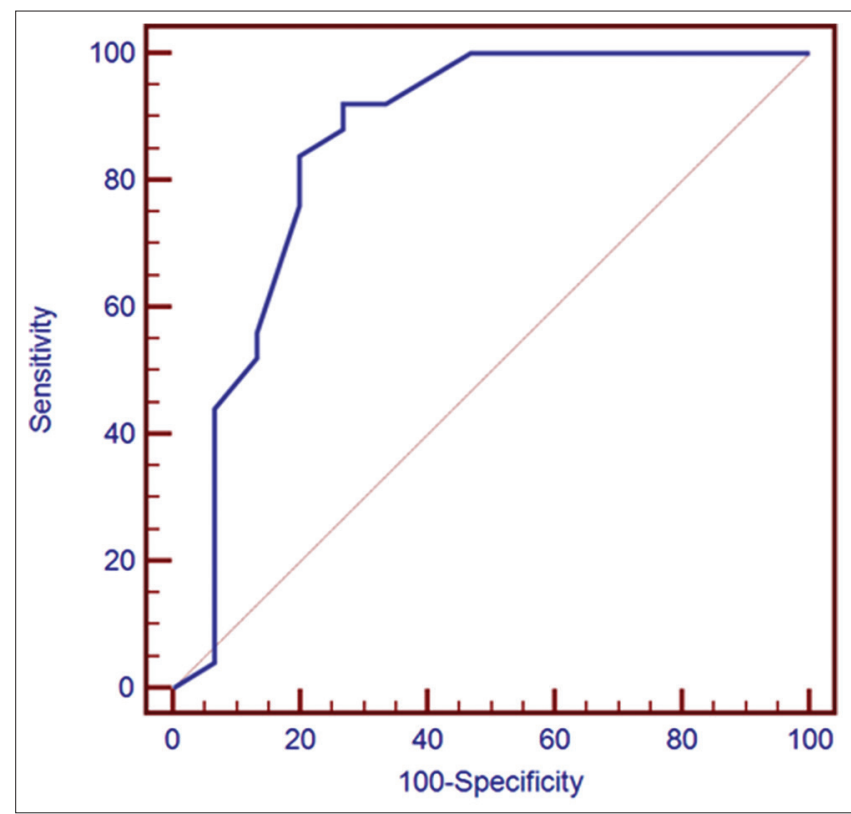

Figure 2: Sensitivity and specificity of left ventricular outflow tract velocity time integral variability index

Table 3: Echocardiographic measures of the studied groups

\begin{tabular}{|c|c|c|c|c|c|}
\hline \multirow{2}{*}{ Hemodynamic parameter } & \multicolumn{3}{|l|}{ Fluid_responsiveness } & \multirow[t]{2}{*}{ t-value } & \multirow[t]{2}{*}{$\mathrm{p}$-value } \\
\hline & All patients no. $=120$ & Group 1 no. $=75$ & Group 2 no. $=45$ & & \\
\hline IVC collapsibility index median (IQR) & $35.5(10-43.5)$ & $40(37-47)$ & $8(4-10)$ & -9.064 & $<0.001$ \\
\hline LVOT VTI variability index median (IQR) & $22(20-23)$ & $22.6(22-23)$ & $19.4(18.7-21)$ & -6.568 & $<0.001$ \\
\hline CO increase (\%) median (IQR) & $9.32(4.87-20.46)$ & $16.56(8.17-23.08)$ & $0.58(0-8.89)$ & -6.613 & $<0.001$ \\
\hline
\end{tabular}

CO: Cardiac output; LVOT VTI: Left ventricular outflow tract velocity time integral; IVC: Inferior vena cava. 
variability index), both were measured before and after fluid resuscitation.

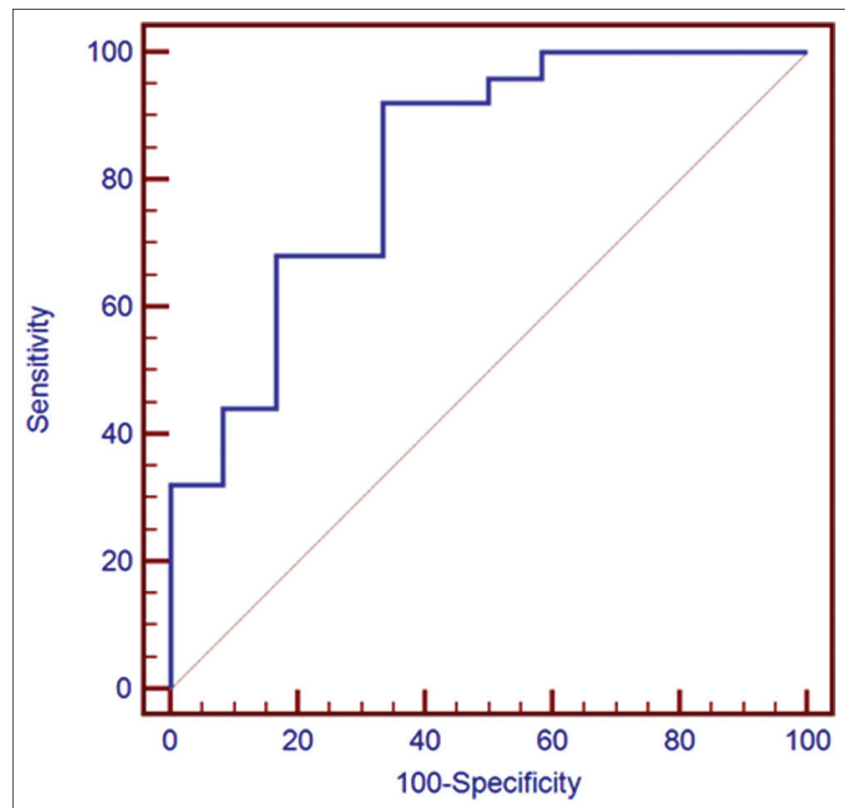

Figure 3: Sensitivity and specificity of cardiac output change

Michard and Teboul, 2002 [13], compared different dynamic and static echocardiographic measures for the prediction of fluid responsiveness in 334 ICU shocked patients and concluded that dynamic measures mainly IVC collapsibility index and LVOT VTI variability index were more accurate and predictive than

Table 4: Sensitivity and specificity of echocardiographic measures of the studied groups

\begin{tabular}{lllllll}
\hline Parameter & AUC & Cutoff point & Sensitivity & Specificity & PPV & NPV \\
\hline IVC collapsibility index & 0.995 & $>18$ & 100.0 & 93.33 & 96.2 & 100.0 \\
LVOT VTI variability index & 0.857 & $>20.5$ & 92.0 & 73.33 & 85.2 & 84.6 \\
CO increase & 0.827 & $>5.66$ & 92.00 & 66.67 & 85.2 & 80.0 \\
\hline
\end{tabular}
\begin{tabular}{lllllrr}
$\mathrm{CO}$ increase & 0.827 & $>5.66$ & 92.00 & 66.67 & 85.2 & 80.0 \\
\hline CO: Cardiac output; LVOT VTI: Left ventricular outflow tract velocity time integral; IVC: Inferior vena cava.
\end{tabular}

static measures. The same was concluded by Huggins et al., 2015 [11], and Miller and Mandeville, 2016 [14]. The latter study found that LVOT VTI variability index and IVC collapsibility index through respiratory cycle of $\geq 12 \%$ predict fluid responsiveness. Furthermore,

Table 5: Central venous line insertion

\begin{tabular}{llllll}
\hline CVL & All patients (\%) & Group 1 no.=75 (\%) & Group 2 no.=45(\%) & Test value & p-value \\
\hline -ve & $87(72.5)$ & $72(96.0)$ & $15(33.3)$ & $55.398^{*}$ & 0.0000 \\
+ +ve & $33(27.5)$ & $3(4.0)$ & $30(66.7)$ & & \\
\hline
\end{tabular}

Coen et al., 2014 [15], studied fluid responsiveness in 47 patients with septic shock, using IVC collapsibility and confirmed that IVC collapsibility index is good predictor of fluid responsiveness. Moreover, the study of Zhao and Wang, 2016 [16], on 42 septic patients concluded that IVC collapsibility index $<15 \%$ indicates

Table 6: In-hospital mortality of the studied groups

\begin{tabular}{|c|c|c|c|c|}
\hline In-hospital mortality & $\begin{array}{l}\text { Group } 1 \\
\text { No. (\%) }\end{array}$ & $\begin{array}{l}\text { Group } 2 \\
\text { No. (\%) }\end{array}$ & Test value & $p$-value \\
\hline Survive & 69 (92.0) & $18(40.0)$ & 38.144 & 0.000 \\
\hline Mortality & $6(8.0)$ & $27(60.0)$ & & \\
\hline
\end{tabular}

fluid unresponsiveness. Another 438 patients study provided similar conclusions [17].

The use of echocardiography allowed us to avoid unduly use of central venous catheter in $72.5 \%$ of the cases and hence its complications, especially in these patients with high bleeding tendency. This result matches with Coen et al., 2014 [15], who studied 47 patients with septic shock, used the variability of IVC diameter to decide the volume responsiveness, and found that central venous catheter was avoided in more than one-third of the patients.

Furthermore, De Lorenzo et al. [18] who carried out a prospective study on 72 patients to investigate volume responsiveness by bedside assessment of IVC and its relation with CVP, they concluded that the subxiphoid ultrasonography IVC assessment is the most reliably correlated with CVP aiming to avoid unduly use of central venous catheter.

Huggins et al., 2016 [11], in a case study, demonstrated that the use of echocardiography improves assessment of volume status in cirrhosis and HRS using IVC collapsibility index and LVOT VTI variability index.

\section{Conclusions}

The use of echocardiography is a good tool for hemodynamic monitoring of fluid resuscitation in cirrhotic patients with AKI. It limited the use of CVL to patients with hemodynamic instability who needed vasoactive support.

\section{References}

1. Fernández J, Aracil C, Solà E, Soriano G, Cardona MC, Coll S, et al. Evaluation and treatment of the critically III cirrhotic patient. Gastroenterol Hepatol. 2016;39(9):607-26. https://doi. org/10.1016/j.gastre.2016.10.004 PMid:26778768

2. Olson JC. Intensive care management of patients with cirrhosis. Curr Treat Options Gastroenterol. 2018;16(2):241-52.

PMid:29616404

3. Risør LM, Bendtsen F, Møller S. Immunologic, hemodynamic, and adrenal incompetence in cirrhosis: Impact on renal dysfunction. Hepatol Int. 2015;9(1):17-27. https://doi. org/10.1007/s12072-014-9581-1 PMid:25788375

4. Muciño-Bermejo J, Carrillo-Esper $\mathrm{R}$, Uribe $\mathrm{M}$, MéndezSánchez N. Acute kidney injury in critically III cirrhotic patients: A review. Ann Hepatol. 2012;11(3):301-10. https://doi.org/10.1016/ s1665-2681(19)30924-x

PMid:22481447 
5. Qasem AA, Farag SE, Hamed E, Emara M, Bihery A, Pasha H. Urinary biomarkers of acute kidney injury in patients with liver cirrhosis. ISRN Nephrol. 2014;2014:376795. https://doi. org/10.1155/2014/376795

6. El Sharkawy OA, Refaat EK, Ibraheem AE, Mahdy WR, Fayed NA, Mourad WS, et al. Transoesophageal Doppler compared to central venous pressure for perioperative hemodynamic monitoring and fluid guidance in liver resection. Saudi J Anaesth. 2013;7(4):378-86. https://doi. org/10.4103/1658-354x.121044

PMid:24348287

7. Mehta RL, Kellum JA, Shah SV, Molitoris BA, Ronco C, Warnock DG, et al. Acute kidney injury network: Report of an initiative to improve outcomes in acute kidney injury. Crit Care. 2007;11(2):R31. https://doi.org/10.1186/cc5713

PMid: 17331245

8. Salerno F, Gerbes A, Ginès P, Wong F, Arroyo V. Diagnosis, prevention and treatment of hepatorenal syndrome in cirrhosis. Gut. 2007;56(9):1310-8. https://doi.org/10.1136/ gut.2006.107789

PMid:17389705

9. Balogh Z, Jones F, D'Amours S, Parr M, Sugrue M. Continuous intra-abdominal pressure measurement technique. Am J Surg. 2004;188(6):679-84. https://doi.org/10.1016/j. amjsurg.2004.08.052 PMid:15619483

10. Messina A, Longhini F, Coppo C, Pagni A, Lungu R, Ronco C, et al. Use of the fluid challenge in critically III adult patients: A systematic review. Anesth Analg. 2017;125(5):1532-43. https:// doi.org/10.1213/ane. 0000000000002103

PMid:28514324

11. Huggins JT, Doelken P, Walters C, Rockey DC. Point-ofcare echocardiography improves assessment of volume status in cirrhosis and hepatorenal syndrome. Am J Med Sci. 2016;351(5):550-3. https://doi.org/10.1016/j. amjms.2016.02.040

PMid:27140719
12. Warner NS, Cuthbert JA, Bhore R, Rockey DC. Acute kidney injury and chronic kidney disease in hospitalized patients with cirrhosis. J Investig Med. 2011;59(8):1244-51. https://doi. org/10.2310/jim.0b013e3182321471

PMid:21941210

13. Michard F, Teboul JL. Predicting fluid responsiveness in ICU patients: A critical analysis of the evidence. Chest. 2002;121(6):2000-8. https://doi.org/10.1378/chest.121.6.2000 PMid:12065368

14. Miller A, Mandeville J. Predicting and measuring fluid responsiveness with echocardiography. Echo Res Pract. 2016;3(2):G1-12. https://doi.org/10.1530/erp-16-0008 PMid:27249550

15. Coen D, Cortellaro F, Pasini S, Tombini V, Vaccaro A Montalbetti $\mathrm{L}$, et al. Towards a less invasive approach to the early goal-directed treatment of septic shock in the ED. Am J Emerg Med. 2014;32(6):563-8. https://doi.org/10.1016/j. ajem.2014.02.011

PMid:24666743

16. Zhao J, Wang G. Inferior vena cava collapsibility index is a valuable and non-invasive index for elevated general heart end-diastolic volume index estimation in septic shock patients. Med Sci Monit. 2016;22:3843-8. https://doi.org/10.12659/ msm.897406 PMid:27762259

17. Gan H, Cannesson M, Chandler JR, Ansermino JM. Predicting fluid responsiveness in children: A systematic review. Anesth Analg. 2013;117(6):1380-92. https://doi.org/10.1213/ ane.0b013e3182a9557e PMid:24257389

18. De Lorenzo RA, Morris MJ, Williams JB, Haley TF, Straight TM, Holbrook-Emmons VL, et al. Does a simple bedside sonographic measurement of the inferior vena cava correlate to central venous pressure? J Emerg Med. 2012;42(4):429-36. https://doi. org/10.1016/j.jemermed.2011.05.082

PMid:22197199 